\title{
Effect of ultrasound on protein metabolism in the silkworm, Bombyx mori (L.)
}

\author{
Murali Mohan, P.*1, Siva Prasad, S. ${ }^{2}$, and Sahitya Chetan, P. ${ }^{3}$ \\ ${ }^{1}$ Department of Sericulture, SP Mahila University, TIRUPATI-517502, India, Email: profpmuralimohan@gmail.com \\ ${ }^{2}$ Department of Zoology, Smt. N.P.S. Government College for Women, Chittoor- 517002, India \\ ${ }^{3}$ Scuola Internazionale Superiore Studi Avanzati (SISSA), Via Bonomea, No. 265 Trieste - 34136, Italy
}

\begin{abstract}
The parameters of protein metabolism, such as the levels of soluble, structural and total proteins, free amino acids, and the activity levels of protease, aspartate and alanine aminotransferases and glutamate dehydrogenase were assayed in the hemolymph, silk-gland, muscle and fat-body on different days of the $5^{\text {th }}$ instar larva of the silkworm, Bombyx mori, following exposure of the silkworm eggs to $1 \mathrm{MHz}$ continuous wave of ultrasound at an intensity of $9 \mathrm{~W} / \mathrm{cm}^{2}$ for 2 minutes. Ultrasound was found to promote the accumulation of proteins, which include silk proteins as well, while retarding proteolysis and turnover of proteins towards the release of amino acids, keto-acids etc. Changes in the levels of these biochemical constituents are correlated with the events of histogenesis and histolysis associated with metamorphosis. It may be inferred that protein metabolism is stimulated by ultrasound, resulting in greater turnover of silk proteins, spinning activity and silk output.
\end{abstract}

Key words: Ultrasound, Silkworm, Bombyx mori, Proteins, Amino Acids, Protease, Aminotransferases, Glutamate dehydrogenase.

DOI: http://dx.doi.org/10.4314/ejst.v7i2.1

\section{INTRODUCTION}

Insect metamorphosis is a dynamic biochemical activity. Chen (1971) highlighted the role of biochemical constituents in insect metamorphosis. Since the silkworm is an economically important insect, several insect physiologists attempted to elucidate the role of biochemical constituents in silk protein synthesis and egg formation (Horie et al., 1971; Mathavan et al., 1984). The growth of silkworm during metamorphosis is accompanied by the increase in the body weight and accumulation of various biochemical constituents like proteins, amino acids and enzymes like proteases, aminotransferases and glutamate dehydrogenase (Pant and Jaiswal, 1981; Bannikov et al., 1982; Wangerli and Xuting-Sen, 1982; Bose et al., 1989; Siva Prasad and Murali Mohan, 1990). More importantly, the parameters of protein metabolism have been extensively examined because of their role in development, morphogenesis and intermediary metabolism (Tojo et al., 1980; Ogawa and Tojo, 1981; Sasaki et al., 1981; Robert and Rutt, 1982; Sarangi, 1985; Ravikumar and Sarangi, 2004).

A novel approach in silkworm research is the manipulation of biochemical machinery through exogenous modulators that could boost the silk production. This included the administration of certain neurohumoral factors, vertebrate hormones and various other chemicals like cyclic AMP and prostaglandins, which could have a profound influence on the growth rate, larval life cycle and fecundity (Singh and Dutta, 1980; Bharathi and Govindappa, 1987; Thyagaraja et al., 1991; Bharathi, 1993). Significant positive impact of vertebrate thyroxine on silkworm biology, especially in improving the pre- and post-cocoon parameters is well documented (Bharathi et al., 1986;

\footnotetext{
*Correspondind author

(C) This is an Open Access article distributed under the terms of the Creative Commons Attribution License (http://creativecommons.org/licenses/CC BY4.0).
} 
Krishnamurthy et al., 1987; Chaudhuri and Medda, 1992). Another vertebrate hormone, namely prolactin, induced improvement in the growth and reproductive potential of silkworms (Bhaskar et al., 1983; Bharathi et al., 1984, 1986). The dietary administration of vertebrate sex hormones like ethynyl estradiol (EE) and norethindrone (NE) to the silkworm increased the larval weight, cocoon and shell weights, female pupal and adult weights, but the larval, pupal periods and the egg-hatchability were significantly reduced (Saha and Khan,1977).

These investigations opened up alternative strategies for improving the economic parameters of the sericulture industry by regulating the biochemical machinery. One such option is the ultrasound, whose impact on larval life in Drosophila has been reported (Child et al., 1981). Further, it was reported that ultrasound irradiation does not cause any detectable deterioration in behavioral responses such as mating, oviposition, larval development and pupation in insects (Koehler et al., 1986). Ultrasound has been used as an exogenous modulator of several parameters in both vertebrate and invertebrate models. However, the mechanism of action of ultrasound in these models has not yet been resolved. A few studies are also available on ultrasound effects on silkworm. Samal et al. (2013) examined ultrasound sonication effects on the properties of silkworm fibroin protein. Murali Mohan and Siva Prasad (2013) studied the effect of ultrasound on economic characters of the silkworm and found improvement in several characters including silk output upon exposure to ultrasound. Since the silk fiber is composed of the protein fibroin, it is important to examine the effect of ultrasound on the silkworm protein metabolic profile. Taking this cue, ultrasound was used in the present investigation for the manipulation of protein metabolism in the silkworm and to examine the possibility of its utility in sericulture.

\section{MATERIALS AND METHODS}

The present investigation was carried out on the hybrid of Pure Mysore variety (Multivoltine) and $\mathrm{NB}_{4} \mathrm{D}_{2}$ variety (Bivoltine) of the silkworm Bombyx mori. The silkworm eggs in blue-egg stage (10-12 h old) were exposed to ultrasound at a frequency of 1 $\mathrm{MHz}$ and an intensity of $9 \mathrm{~W} / \mathrm{cm}^{2}$ for $2 \mathrm{~min}$, using an ultrasound equipment, model WIPRO-GE Alpha-Logic-100. Prior to exposure, the egg-card was kept in a sealed, water-filled polythene bag, smeared with gel so as to prevent the diversion of ultrasonic waves. The bag was suspended in the ultrasonic bath tank. Water can be continuously circulated inside the tank, and its level can be maintained more or less at a fixed height. A transducer was kept at the base of the tank, and it transmits ultrasonic energy to the eggs in a focused way. The duration of exposure was standardized by exposing the eggs to varying intensities of ultrasound waves at different time intervals, viz. 2, 5, 10, 15, 20, 25, and 30 minutes. Promising results were obtained at $1 \mathrm{MHz}$ continuous wave of ultrasound at an intensity of $9 \mathrm{~W} / \mathrm{cm}^{2}$ for 2 minutes. The larvae that emerged from the exposed (experimental) and unexposed (control) eggs were used in the investigation in the $5^{\text {th }}$ instar, which accounts for all the silk biosynthesis and secretion into the lumen of the silk-gland. The treatment of eggs with ultrasound was replicated six times separately. Tissues from at least ten silkworms that emerged from each treated lot of eggs were pooled for biochemical estimations. Daily changes in biochemical parameters of protein metabolism such as proteins, free amino acids, and the activity levels of the enzymes protease, aspartate and alanine aminotransferases, and glutamate dehydrogenase were observed in the $5^{\text {th }}$ instar larvae. Tissues such as hemolymph, silk-gland, muscle and fat-body, isolated by dissecting the larvae in ice-cold silkworm Ringer (Yamaoka et al., 1971) were used for the biochemical assays. The total protein content as well as the soluble protein content was estimated by the method of Lowry et al. (1951). The trend of changes in the structural protein levels 
was obtained by subtracting the soluble protein levels from the total protein levels in both control and experimental worms and then calculating the percent changes for each day of the $5^{\text {th }}$ instar against the respective controls. The free amino acid content was estimated by the method of Moore and Stein (1954) as described by Colowick and Kaplan (1957) and the protease activity by the method of Davis and Smith (1955). The activity levels of aspartate aminotransferase (AAT) and alanine aminotransferase (AlAT) were estimated by the method of Reitman and Frankel (1957) as described by Bergmeyer and Bruns (1965) and the activity of glutamate dehydrogenase (GDH) was assayed by the method of Lee and Lardy (1965).

\section{Statistical treatment of data}

The difference in physiological activity between the control and ultrasound-treated (experimental) groups was statistically tested. All the assays were carried out with six separate replicates from each group. Values were expressed as mean \pm standard deviation (SD) from six replicates. The mean and SD were worked out using INSTAT statistical software and Dunnett's multiple comparison test followed by oneway Analysis of Variance (ANOVA) using the SPSS statistical tool (SPSS for windows, release 17.0.1, 2008, SPSS Inc., Chicago, IL) to assess the differences. P values of $<0.05$ were considered as statistically significant. Percentage changes were calculated from control to treated and presented along with the statistical test.

\section{RESULTS}

Tables 1 to 8 and Figures 1 to 8 highlight the changes in the biochemical parameters, viz., proteins, free amino acids, protease, aminotransferases and glutamate dehydrogenase and the effect of ultrasound on these parameters in the $5^{\text {th }}$ instar larvae of Bombyx mori.
The levels of total and soluble proteins recorded an increasing trend in all the tissues from the $1^{\text {st }}$ day to the $6^{\text {th }}$ day of the instar. The extent of increase varied from tissue to tissue. The levels of total proteins registered a maximum increase of $15.4 \%$ on $1^{\text {st }}$ and $4^{\text {th }}$ days in hemolymph, $92.4 \%$ in silk-gland, $71.4 \%$ in muscle and $28.6 \%$ in fat-body on the $6^{\text {th }}$ day of the $5^{\text {th }}$ instar. Thus, ultrasound treatment elevated the total protein level in all the tissues. However, the increase was not progressive and consistent in hemolymph on different days of the instar (Table 1).

The levels of soluble proteins showed a steady increase from the $1^{\text {st }}$ day to the $6^{\text {th }}$ day of the instar. However, in the worms treated with ultrasound, lower increases in the levels of soluble proteins were evident in all the tissues. This trend was inconsistent in the hemolymph, with greater increases on certain days and lower increases on the other days. The changes in hemolymph were statistically not significant (Table 2).

The structural protein levels showed slight increases in hemolymph on different days of the instar. In the remaining tissues their levels increased progressively throughout, reaching the maximum by the $6^{\text {th }}$ day. High increases were recorded in the silk-gland (169.7\%) and muscle (332.7\%) on the $6^{\text {th }}$ day (Table 3$)$.

Under the impact of ultrasound, the levels of total free amino acids showed a progressive increase in different tissues on all days of the instar. When the percent increases were calculated against the controls for each day, the increases were found to be relatively small and there was no discernible trend. Except in hemolymph (from the $3^{\text {rd }}$ day), the increases in all other tissues were not statistically significant (Table 4). 


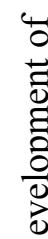

$\frac{5}{a}$

ह

$\stackrel{0}{\rightleftarrows}$

目

ว

है

$\bar{c}$

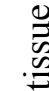

$\stackrel{ \pm}{ \pm}$

(1)

:

要

on

a

ฮ

:

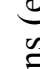

$+2$

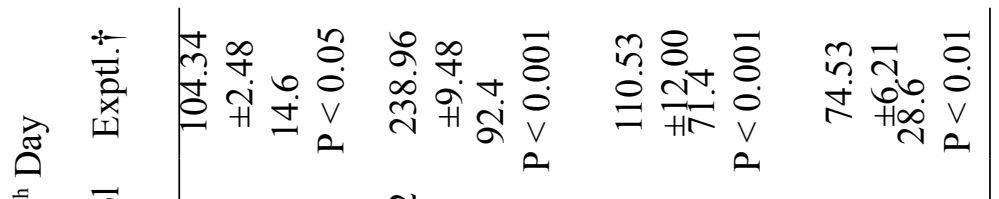

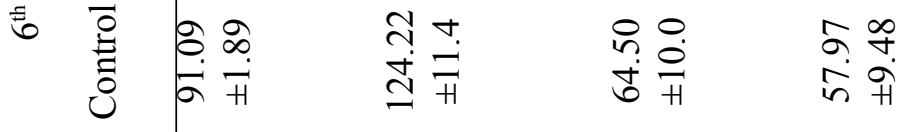

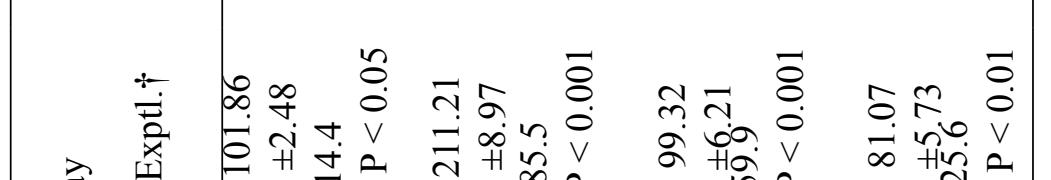

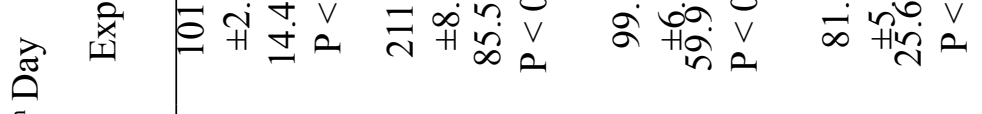
i 竞

C.

$\infty$
$\infty$
$\dot{0}$
$=$

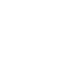

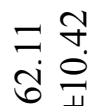

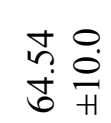

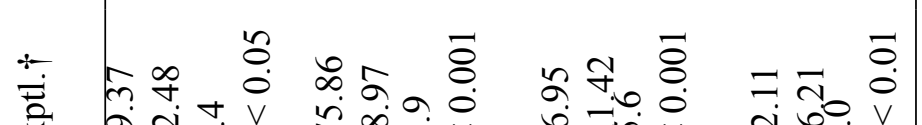

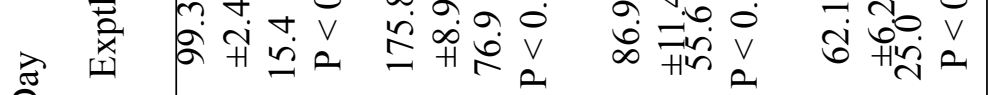
吾

F

$\frac{1}{0}: \frac{1}{2}$

$\therefore$ 卉

aें

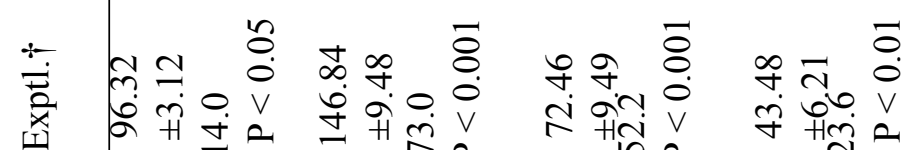

$\rightarrow$

ค 离

홍

$\underset{\infty}{\infty}$

$\infty$
$\infty$
$\dot{\infty}$
$\dot{\infty}$ $\sim a$

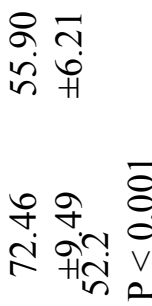

ํㅜㅁ

के 아

గ్ర

字贲

जे

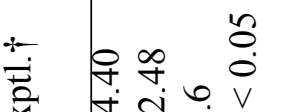

भि. $\overline{8}$

$=$ 궁

$\approx \vec{\sim} \stackrel{\overrightarrow{0}}{\circ}$

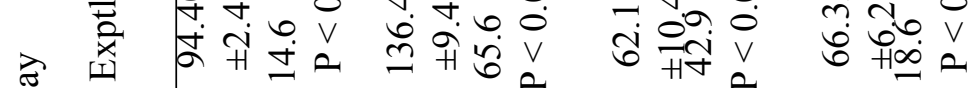

总

泀

$\underset{\infty}{\infty} \underset{\infty}{\stackrel{1}{+}}$

$\stackrel{\infty}{+} \bar{i}$

ซे

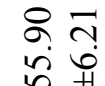

$+\quad+\infty \stackrel{0}{0}$

ำ

$\stackrel{\infty}{\circ}$

in

章

齐完范

ปํ 배

可

8

के

กิ

लें

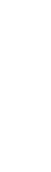

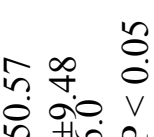

$\infty$

हि

8 in

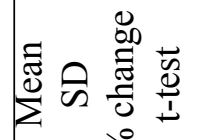

焉部喜

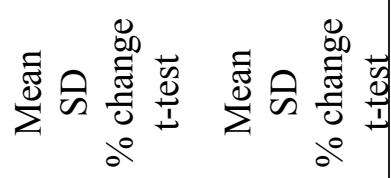

$\stackrel{\infty}{\stackrel{\infty}{\sim}}$

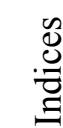

ह્.

$\stackrel{0}{\mathscr{n}}$

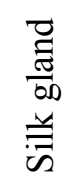

$\frac{0}{0}$

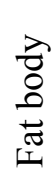

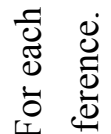

D.

?

政

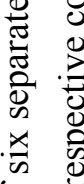

空

营

3
0
0
$\frac{0}{3}$
$\frac{0}{\pi}$
0
0
0
0

ฮี

하

$\because$

要

गี

I.

言

呈

훙

एँ

造

풀 흥

है

0.

总

穿. 


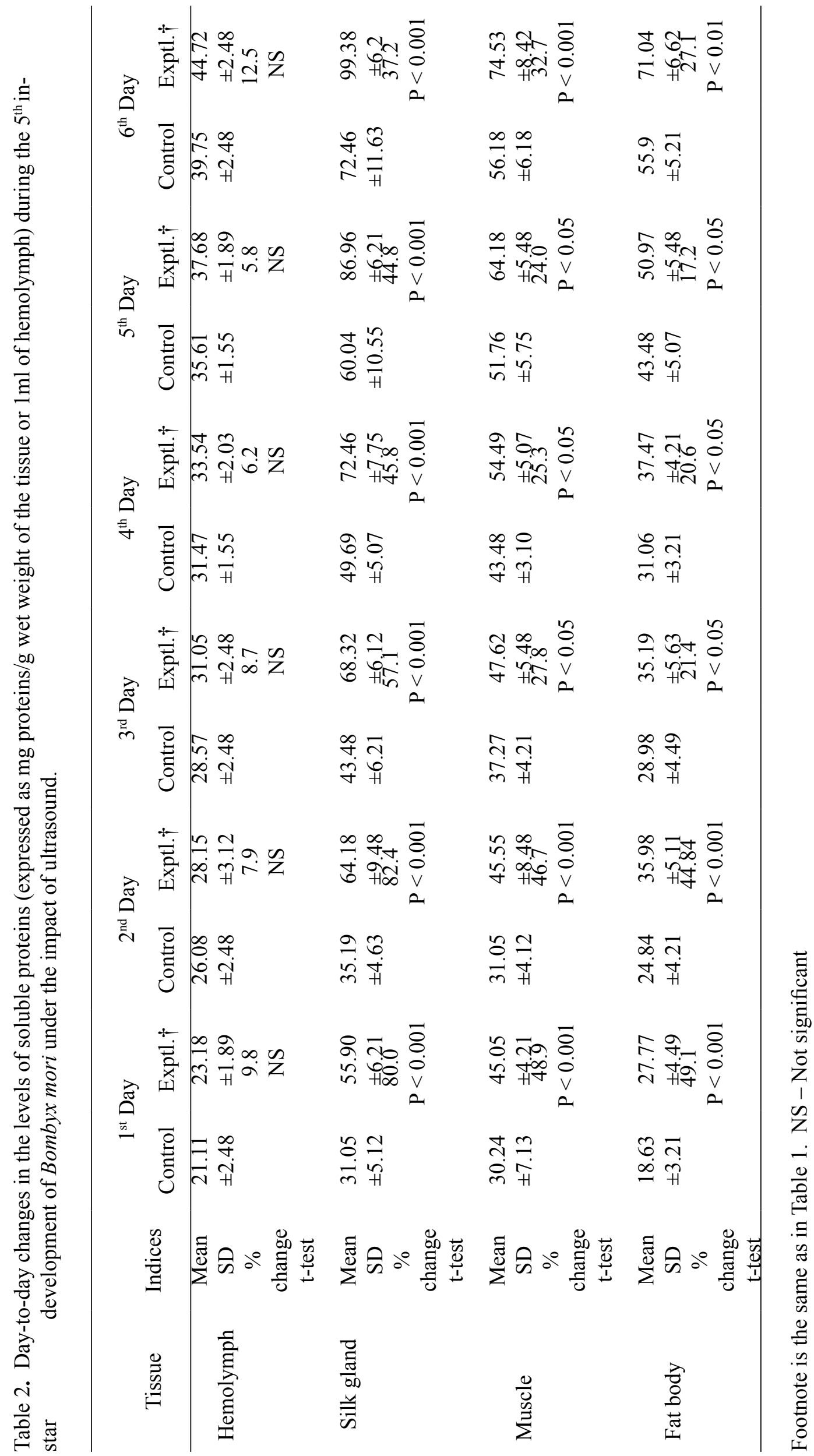




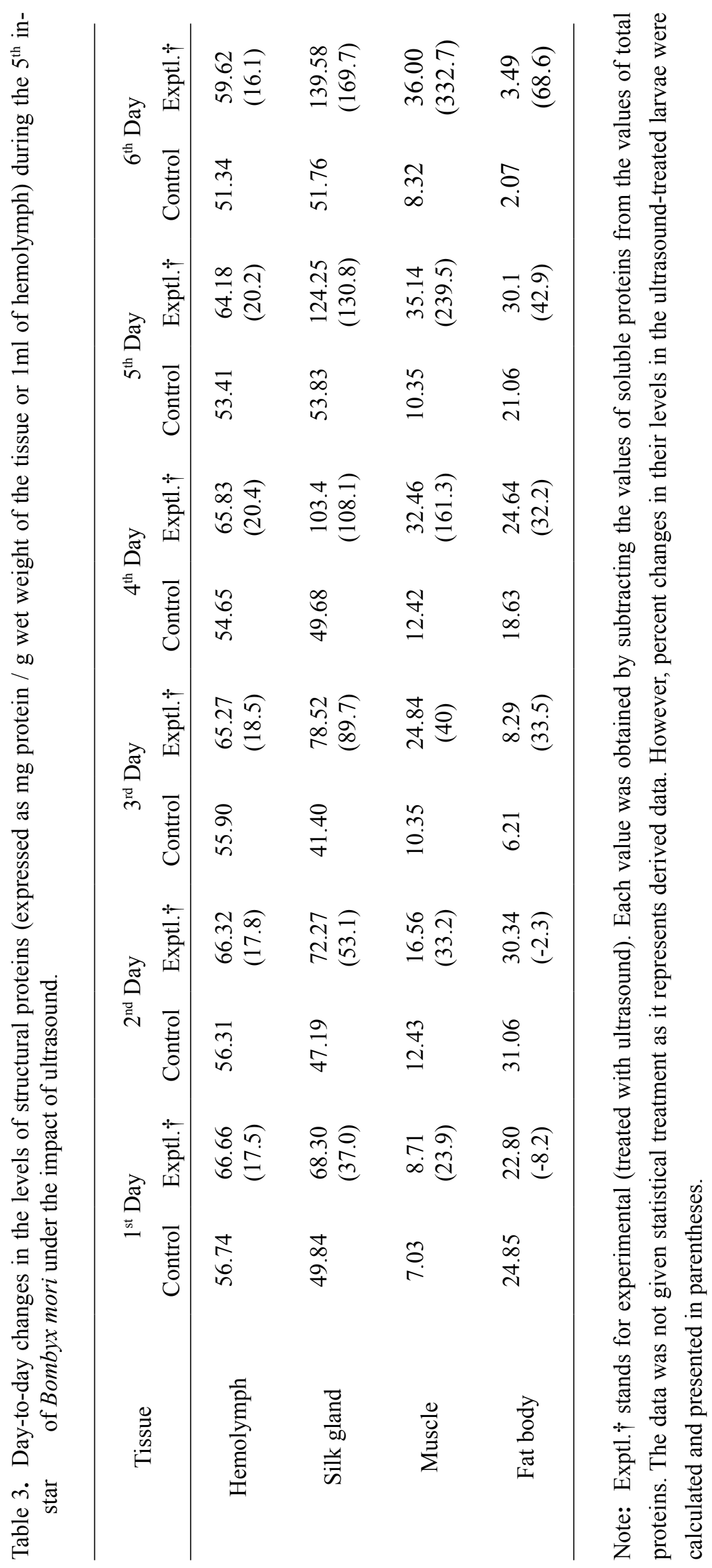




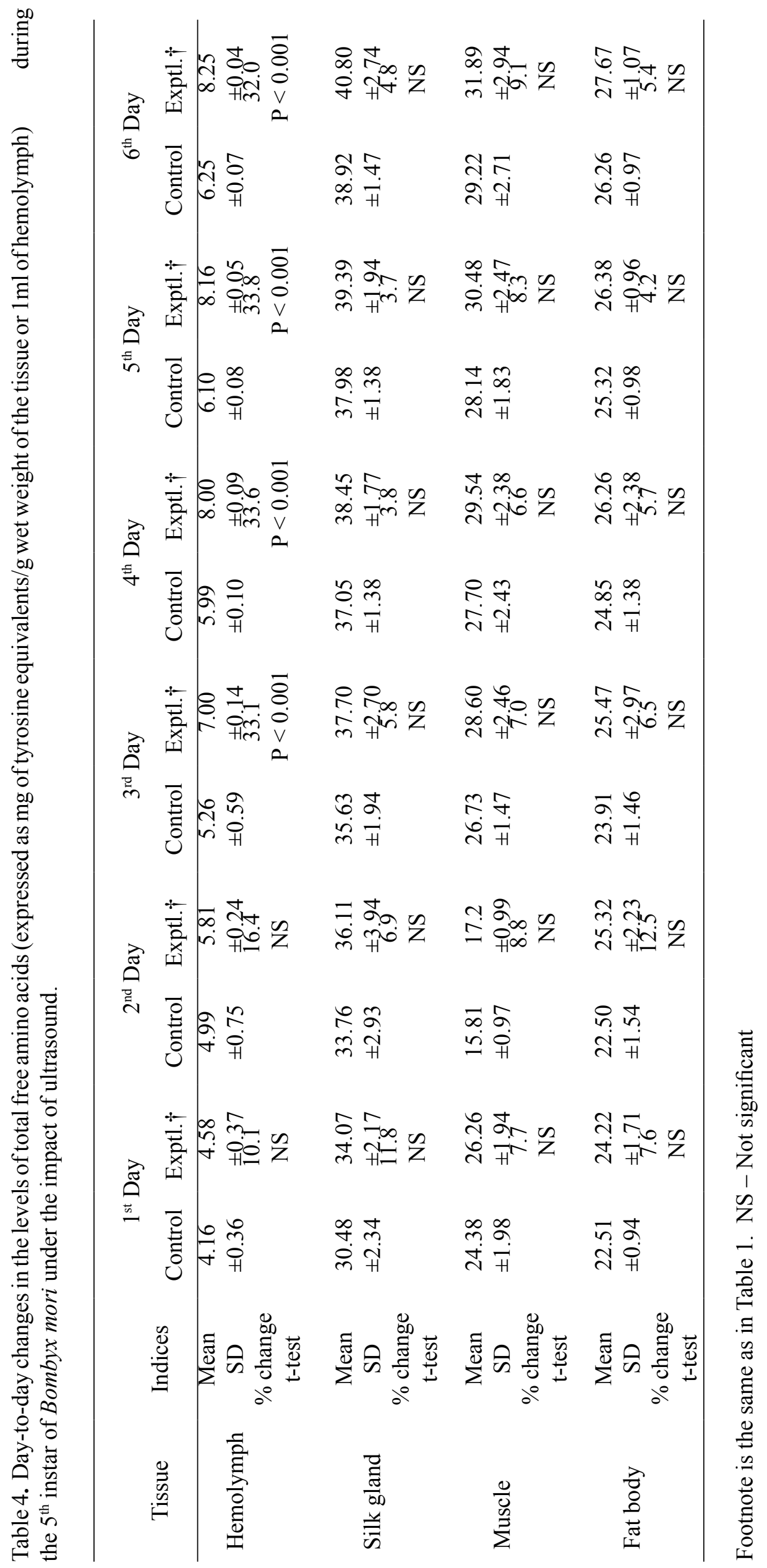


The activity levels of protease recorded slight elevations in all the tissues throughout the instar, both in the control and experimental silkworms. In general, the elevations were found to be progressively lowered as the instar progressed from the $1^{\text {st }}$ day to the $6^{\text {th }}$ day in the case of hemolymph, silk-gland and muscle, while the percent increase was progressive with the days of the instar. The basic levels of protease activity were more or less similar in all the four tissues. Except in the muscle, the increases in activity in all the other tissues were not statistically significant (Table 5).

The activity of aspartate aminotransferase (AAT) maintained relatively constant levels in the hemolymph both in the control and experimental silkworms on all days of the instar without any perceptible variation. In silk-gland and muscle the enzyme activity recorded marginal percent increases on all the days of the instar both in the control and experimental silkworms, but without any particular trend. These small increases were not statistically significant. However, in the case of fat-body, the AAT activity showed progressive percent increases in the silkworms under the impact of ultrasound as the instar progressed, and the changes were statistically significant (Table 6).

The alanine aminotransferase (AlAT) activity by and large showed a similar trend as of AAT, with marginal percent increases under the impact of ultrasound on all days of the instar. However, in hemolymph, silk-gland and muscle, these slight increases got progressively lowered as the instar progressed. These percent increases were statistically not significant. However, in the case of fat-body, the AlAT activity showed a trend that was similar to the one exhibited by AAT activity, with progressive percent increases in the silkworms under the impact of ultrasound as the instar progressed. These changes were statistically significant from the $4^{\text {th }}$ day onwards (Table 7). Although not statis- tically significant, the percentage changes in glutamate dehydrogenase (GDH) activity progressively rose in all the tissues of the silkworms under the influence of ultrasound. These increases were marginal and statistically not significant in the case of silk-gland and fat-body, and significant only on the $5^{\text {th }}$ and $6^{\text {th }}$ days of the instar in the muscle. In the hemolymph the percent increases were statistically significant from the $3^{\text {rd }}$ day onwards (Table 8).

\section{DISCUSSION}

In the present study, ultrasound was in general found to have a stimulatory effect on the protein metabolism. Since proteins are the chief organic constituents regulating the biochemical events in the cell, it appears logical that ultrasound has a stimulatory effect on the protein metabolism. Although increased levels of proteins were observed in silkworm tissues (Zaidi and Khan, 1979: Tojo et al., 1980; Siva Prasad and Murali Mohan, 1990), these parameters have not been hitherto analyzed with reference to ultrasound in the silkworm. However, reports are available on the effect of ultrasound on protein synthesis with reference to differential tissue response in other animals (Lele et al., 1973).

Proteins perform multiple functions. The hemolymph proteins are implicated in ecdysis, growth of reproductive organs and salivary glands, formation of hemocytes and chitin (Zaidi and Khan, 1979; Gakhar and Maleyvar, 1985). In muscle, most of these proteins are contractile that facilitate feeding and spinning behaviors of silkworm (Siva Prasad and Murali Mohan, 1990). Obviously, the intensification of these two behaviors is of paramount importance in $5^{\text {th }}$ instar larvae. The feeding behavior is more pronounced in early stages and is responsible for the uptake of the nutrients, while the spinning behavior manifests at the end of the $5^{\text {th }}$ instar and is responsible for spinning of the cocoon. As such, the prevalence of higher levels of structural 


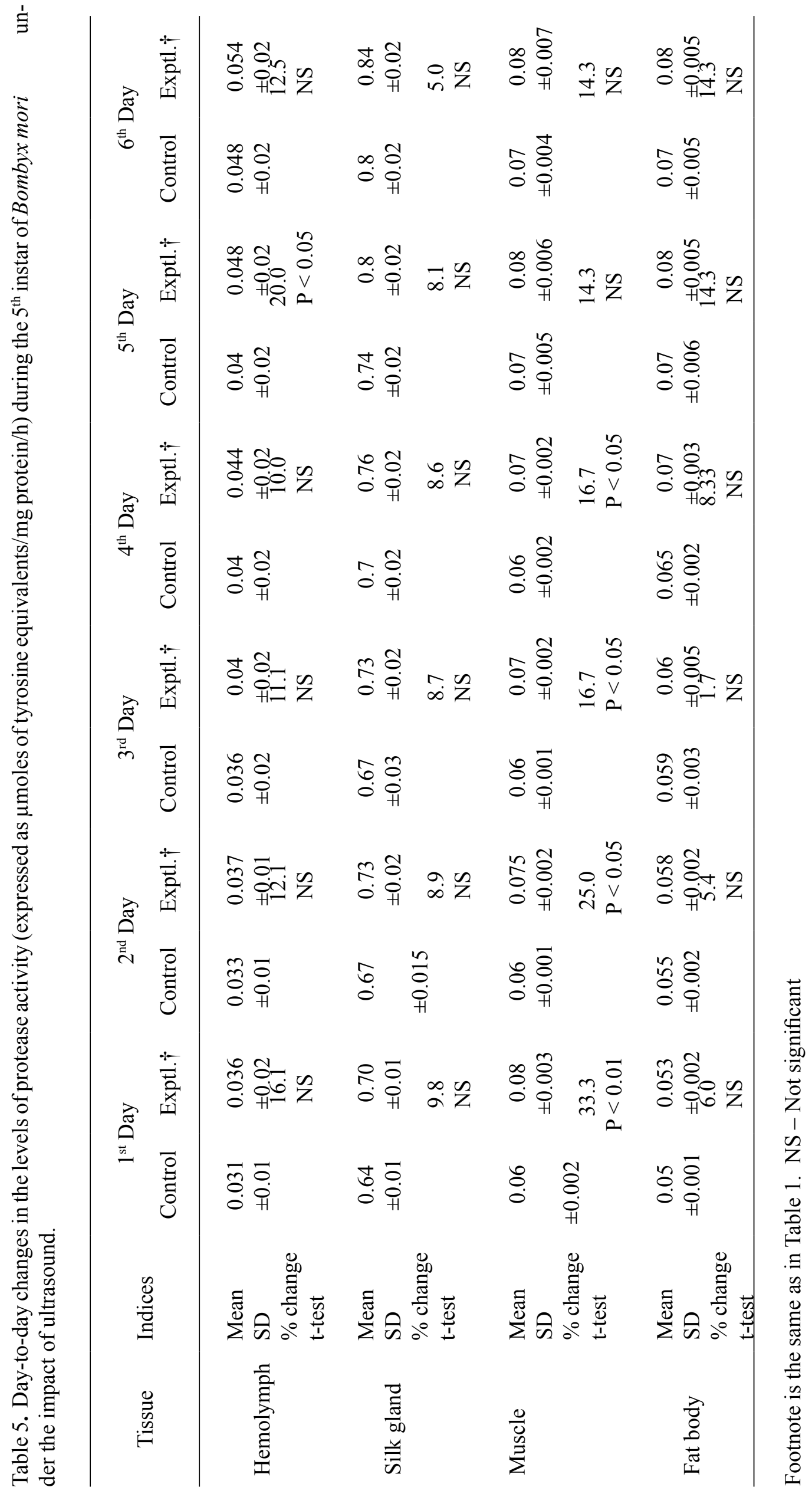




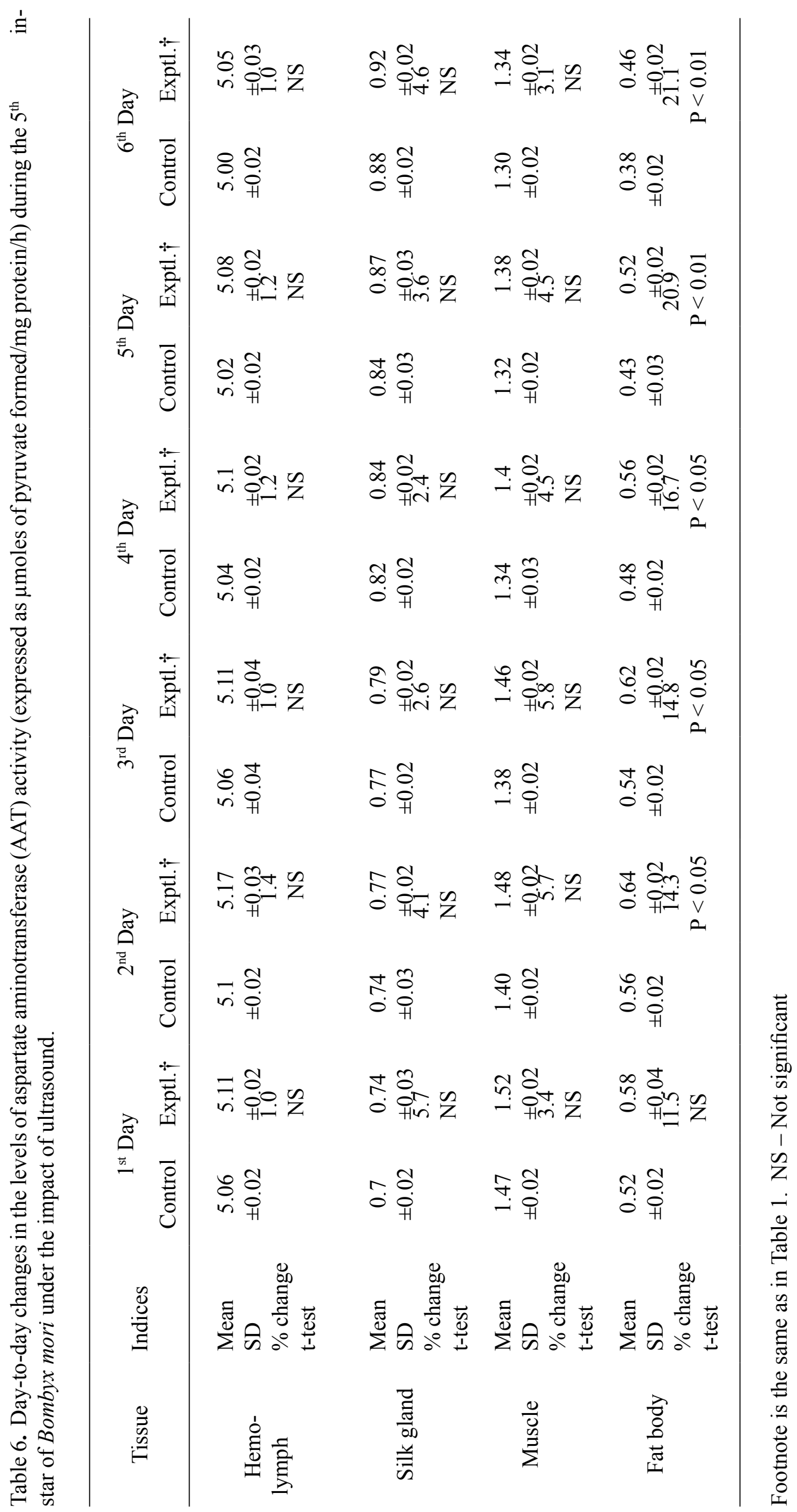


.

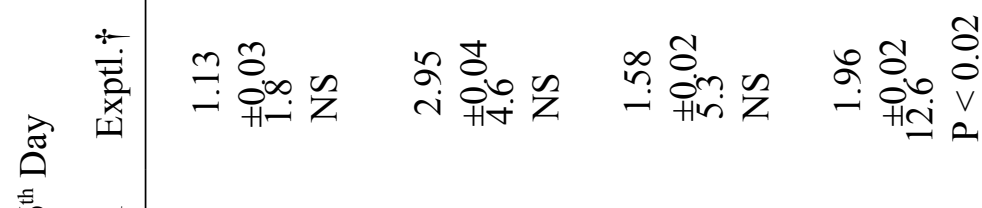

$\underset{0}{ \pm}$

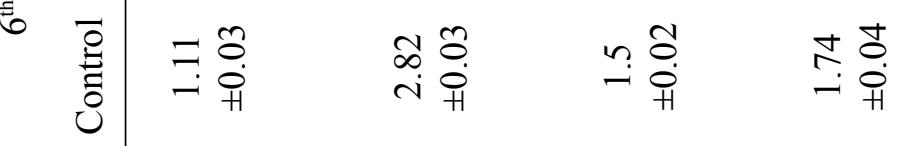

咅

tت 死齐

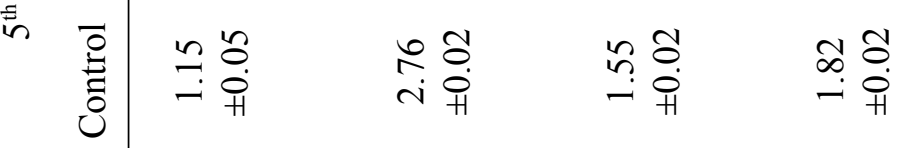

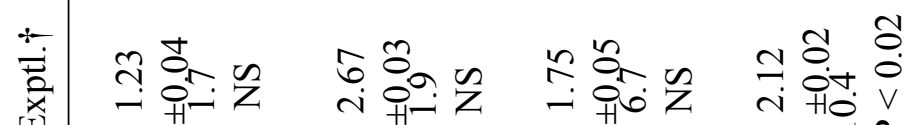

ᄅ.

i

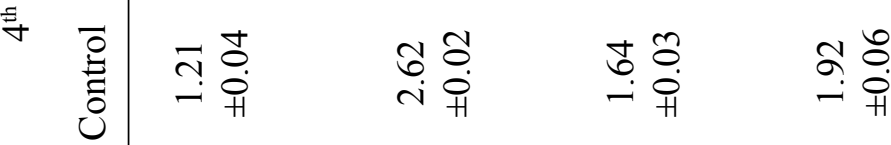

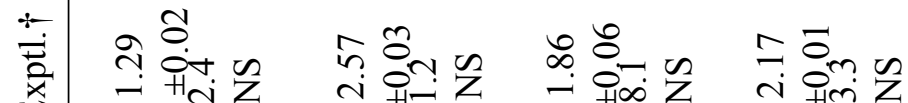

ब文

:

m

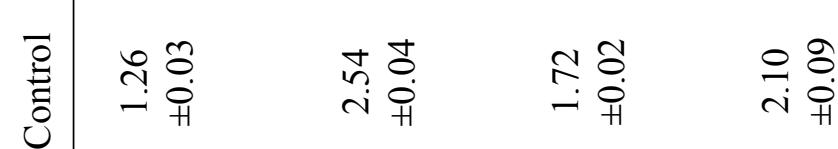

安

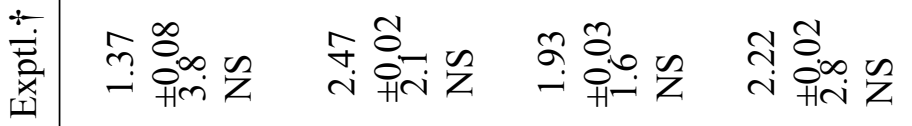

తి

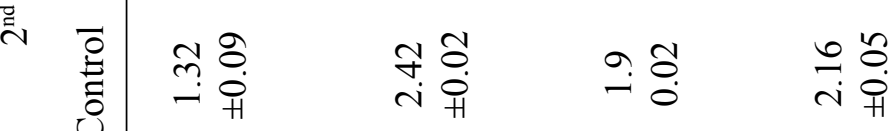

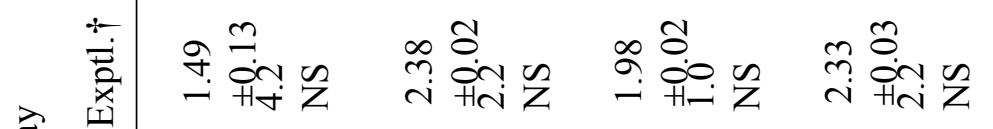

อิ

.

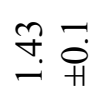

๗ి

当

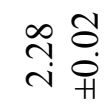

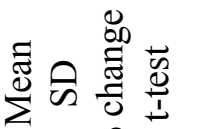

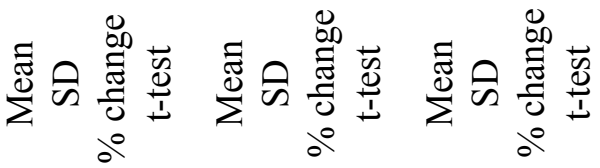

Z

这

त)

.

ฮี

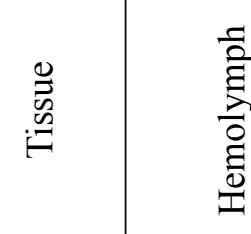

竞

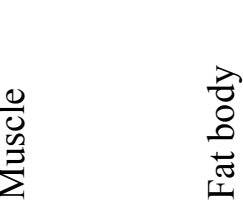




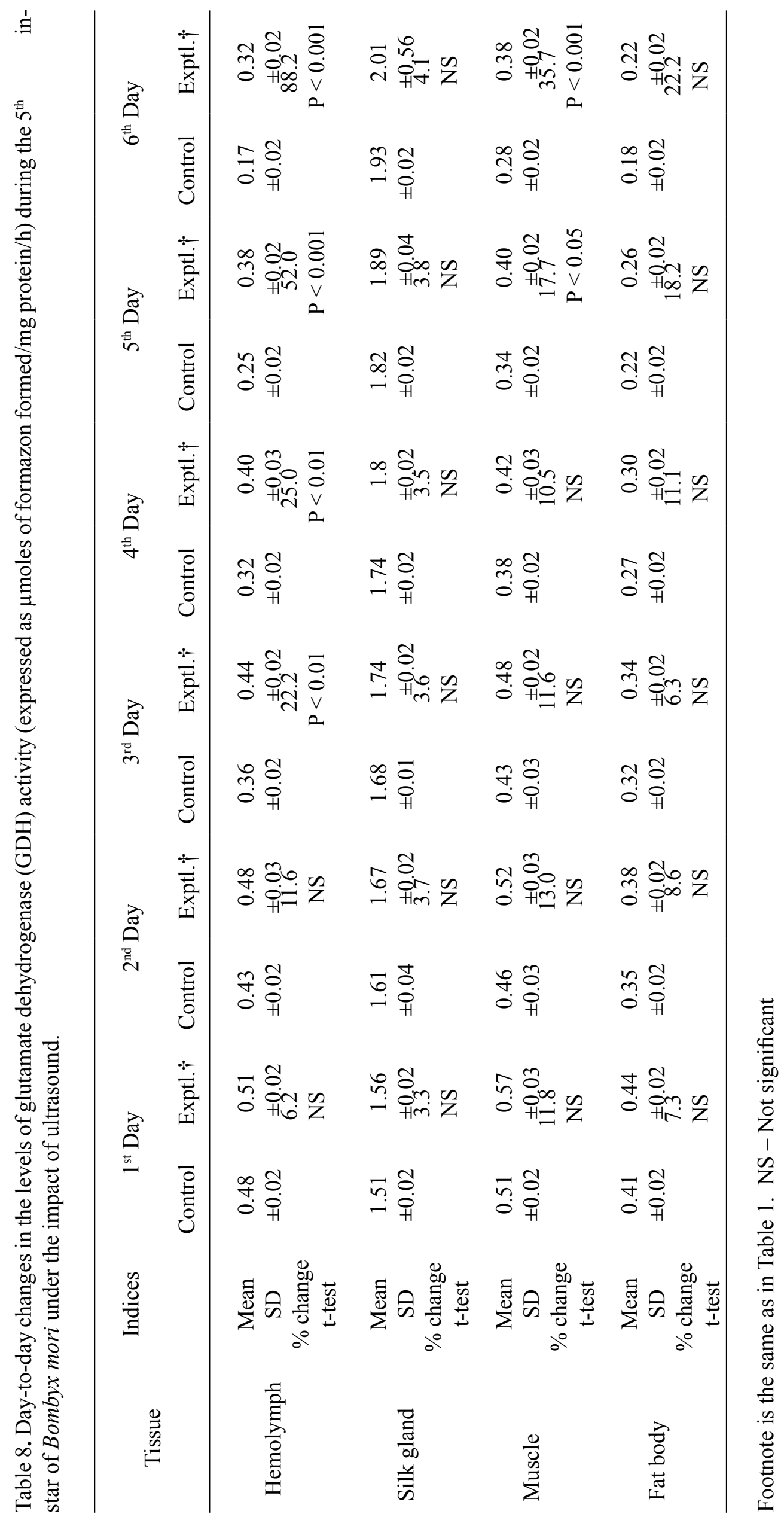


proteins during the $5^{\text {th }}$ instar (Table 3 ) is indicative of strengthening of the muscle tissue for increased efficiency of feeding behavior during the larval development. Further, the increases in the levels of structural proteins coupled with the increase in the levels of total and soluble proteins is indicative of the ongoing histolysis associated with the degenerative metamorphic changes and delegation of proteins towards the spinning activity as well as the formation of the silk proteins in the silk-gland. In silk-gland, the proteins are used for the synthesis of silk proteins, viz., fibroin and sericin (Horie et al., 1971). The phenomenal increase in the levels of structural proteins (Table 3 ) in silk-gland and muscle is indicative of the continuous synthesis and accumulation of the silk proteins. The fat-body seems to act as the storage organ similar to that of liver in vertebrates (Price, 1973). Further, hemolymph presumably acts as a transitory repository of biochemical constituents, into which the tissues leak out their biochemical constituents and retrieve them when needed. Thus, a dynamic biochemical exchange mechanism seems to operate in silkworm and other insects, facilitating the exchange of substances between the fat-body and hemolymph (Martin et. al., 1971; Noguchi et al., 1974; Sarangi, 1985; Nagata and Kobayashi, 1990; Ravikumar and Sarangi, 2004). Ultrasound presumably enhances the absorption of soluble proteins from the hemolymph and fat-body. The mechanism by which ultrasound causes changes in silkworm is not yet known. The Increased levels of total, soluble and structural proteins in silkworm tissues indicate the growth-promoting nature of ultrasound when applied in lower dosages and indicate a promising future for the sericultural industry. Apparently, ultrasound seems to enhance the protein synthesis in general, with a bias towards the silk proteins in the silk-gland and contractile proteins in the muscle. Interestingly, the greater accumulation of structural proteins in the muscle $(332.7 \%)$ following the ultrasound treat- ment deserves some attention, and it is indicative of the promising role of ultrasound in consolidating protein levels in tissues. Such consolidation could provide the required tensile strength to the muscles, facilitating active spinning of the cocoon at the end of $5^{\text {th }}$ instar.

Amino acids are the building blocks of proteins. Ultrasound irradiation caused an elevation in the levels of free amino acids in all the tissues, although to a relatively smaller degree. The silkworm and other lepidopteran insects are known to contain unusually large amounts of free amino acids (Siva Prasad and Murali Mohan, 1990; Sinha et al., 1991). Insect metamorphosis is a dynamic process involving both histogenesis and histolysis (Horie and Watanabe 1983; Anderson 1984). The levels of structural, soluble and total proteins in hemolymph, silk-gland, muscle and fat-body indicate the presence of histolytic activity in different tissues in the $5^{\text {th }}$ instar larvae and the consequent build-up of proteins in the tissues. The constructive activity in one tissue appears to match the lytic activity in some other tissue. While histogenesis occurs in silkgland, muscle and fat-body and proteins accumulate in the hemolymph, histolysis seems to proceed in other tissues. Obviously, the amino acid pool in the silkworm is derived both from proteins through histolysis and from non-protein sources like carbohydrates and lipids through de novo synthesis. Increase in the levels of free amino acids following ultrasound-treatment is attributable to the synthesis of amino acids from non-protein sources like glucose and fatty acids (Bose et al., 1989), although to a smaller degree. Given the importance of silkworm, it is presumed that amino acids are crucial for the synthesis of fat-body, particularly during larval-pupal transition. It is likely that amino acids are mobilized from other tissues into the silk-gland and fat-body via the hemolymph, as suggested by Noguchi et al. (1974). Through its elevatory effect, ultrasound seems to trigger certain metabolic 
events (Pant and Jaiswal, 1981), such as transamination, lipogenesis, maintenance of homeostasis, energy metabolism, formation of hemocytes etc, by actively mobilizing the amino acid pool from hemolymph and fat-body during metamorphosis.

Proteases are a group of proteolytic enzymes that hydrolyze proteins into amino acids (Chen, 1971). Protease activity levels recorded an overall increase during the $5^{\text {th }}$ instar development. Greater enzyme activity was observed in silk-gland followed by muscle, fat-body and hemolymph. Protease activity has been reported in silkworm and other insects (Eguchi and Iwamoto, 1975; Bharathi and Miao Yungen, 2003). Further, ultrasound caused an elevation in its activity to varying degrees in different tissues. The presence of non-intestinal protease activity in silkworm tissues is attributed to its role in proteolysis, characterizing insect metamorphosis (Chen, 1971). The positive impact of ultrasound on enzyme activity indicates its ability to degrade proteins by activating proteolytic enzymes. Histolysis seems to be more pronounced in silk-gland, muscle and fat-body as evidenced by increased turnover of amino acids in these tissues. This could probably bring about the degeneration of silk-gland during pupal stage, leaving the fat-body that forms the bulk of pupal weight. The significance of protease activity vis-à-vis muscle degeneration needs to be elucidated with appropriate histochemical and biochemical investigations.

Aminotransferases enable the transfer of amino groups of all amino acids except lysine and threonine to 2-oxo-glutarate, oxaloacetate and pyruvate to form glutamate and alanine respectively (Lehninger, 1993). The presence of aspartate (AAT) and alanine (AlAT) aminotransferase activity was detected in hemolymph, silk-gland, muscle and fat-body of silkworm as reported in earlier investigations (Pant and Jaiswal, 1981; Bannikov et al., 1982; Urbesekf 1989; Siva Prasad and Murali Mohan, 1990; Vankata Rami Reddy et al., 1992). Ultrasound caused an elevation in the activity levels of both AAT and AlAT in silkworm tissues (Tables 6,7$)$, indicating increased turnover of amino acids and glutamate-formation during metamorphosis in the silkworm. The elevation in the levels of free amino acids, although to a moderate degree, observed in the present investigation (Table 4) support this assumption. This indicates the crucial role for aminotransferases in protein synthesis in silkworm tissues (Fukuda, 1960). The increase in the levels of both total and soluble proteins (Tables $1,2)$, vis-à-vis aminotransferase activity (Tables $6,7)$ highlights the role of both AAT and AlAT in protein metabolism of silkworm. The impact of ultrasound on aminotransferase activity and protein synthesis is positive, but differs in sensitivity from tissue to tissue. Further, ultrasound seems to enhance protein synthetic activity more through AlAT than through AAT. Presumably AlAT is more sensitive to ultrasound compared to AAT. The role of ultrasound in the manipulation of various metabolic events like glucogenesis, gluconeogenesis, biological oxidations, histolysis and histogenesis (Pant and Jaiswal, 1981; Venkata Rami Reddy et al., 1992) by elevating the levels of aminotransferases needs to be ascertained. Such an approach could be used to shorten the life cycle of silkworm.

Glutamate dehydrogenase (GDH) is an allosteric enzyme localized mainly in the mitochondrial part of the cell and facilitates the transfer of amino groups of amino acids to $\alpha$-ketoglutarate by transamination, forming L-glutamate with the release of ammonia (Lehninger, 1993). It ensures the availability of $\alpha$-ketoglutarate to citric acid cycle, and thus connects protein metabolism with carbohydrate metabolism. Ultrasound showed an elevatory effect on GDH activity in all the tissues of silkworm (Table 8). Some reports are available 
on GDH activity in Bombyx mori (Venkata Rami Reddy et al., 1992). The enhanced activity of GDH in different tissues in the present study is indicative of increased oxidative deamination of glutamate in these tissues. The $\alpha$-ketoglutarate generated by this enzyme is probably used-up in ensuring sperm mobility in silkworm (Osanai et al., 1987). Ultrasound could activate this process and thus may increase the sexual potential of silkworm.

As stated earlier, the mechanism of ultrasound irradiation on silkworm is not yet known. However, ultrasound is known to cause an elevation in the temperature, which in turn alters the rate of protein synthesis by optimizing the activity of enzymes (Woeber, 1965). The increased activity levels of aminotransferases, protease and GDH under the impact of ultrasound indicate this possibility. This aspect warrants elucidation in silkworm.

The role of ultrasound in protein metabolism needs special mention in economically viable insects like the silkworm, in view of its profound and positive impact on biochemical parameters. Under its influence the entire biochemical machinery in silkworm is apparently geared up to synthesise silk proteins in silk-gland and contractile proteins in muscle during $5^{\text {th }}$ instar development. While the former are used up as the raw materials for the cocoon, the latter are used for generating a muscular mechanism necessary for spinning the cocoon at the end of $5^{\text {th }}$ instar. The increase in the concentration of amino acids with concomitant increase in the levels of total, soluble and structural proteins in silkgland and muscle under the impact of ultrasound reflects this fact. Metabolically, silk-gland seems to occupy a preeminent position during the metamorphosis in silkworm, closely followed by the muscle. Through active deamination of amino acids, facilitated by AAT, AlAT and GDH, silk-gland presumably meets some of its energy requirements by way of enhanced intermediary metabolism. The growth and metamorphosis of silkworm are characterized by both constructive (histogenesis) and destructive (histolysis) events, probably triggered by ultrasound, as evidenced by the increased protease activity coupled with increased titers of free amino acids in silkworm tissues. It may be concluded that under the impact of ultrasound protein metabolism is stimulated to achieve greater turnover of silk proteins, greater spinning activity, and consequently greater silk output.

\section{CONCLUSIONS}

Exposure of silkworm eggs to appropriate doses of ultrasound in terms of intensity and duration of exposure would lead to acceleration of protein metabolism with reference to protein and free amino acid levels and the activity levels of protease, aspartate and alanine aminotransferases and glutamate dehydrogenase. The enhancement in protein metabolism would in turn result in the improvement of economic characters of the silkworm, having a positive impact on the profitability of Sericulture.

\section{ACKNOWLEDGEMENTS}

The authors are highly thankful to SP Mahila University, Tirupati for providing the necessary facilities for the investigation. They also express their gratitude to Dr. R.V. Suresh Kumar, Department of Surgery and Radiology, College of Veterinary Sciences, Tirupati, for extending his help in providing access to the ultrasound equipment for exposing the silkworm eggs to ultrasound.

\section{REFERENCES}

Anderson, O.D. (1984). Developmental changes in protein content, volume and amino acid pools in the larval fat body and hemolymph of Calliphora erythrocephala. Comparative Biochemistry and Physiology 77: 161-165.

Bannikov, V.M., Bachikova, A.P., Ushkova, G.Iand Fillippovich, Y.B. (1982). Study on sub cellular localization of some enzymes in silkworm Bom- 
byx mori eggs. Biokhimiya 47: 1386-1391.

Bergmeyer, H.O and Bruns, E. (1965). In: Methods of enzymatic analysis (Bergmeyer, H.A., ed.), Academic Press, New York.

Bharathi, D. (1993). Effect of PGF2 on the organic constituents of haemolymph of silkworm larvae, Bombyx mori (L). Journal of Sericulture 1: $25-28$.

Bharathi, D. Bhaskar, M. Reddanna, P and Govindappa, S. (1984). An attempt to improve the organic constituents in the body of silkworm, Bombyx mori. Sericologia 24: 473-479.

Bharathi, D. Bhaskar, M. Reddanna, P and Govindappa, S. (1986). Effect of vertebrate pituitary extract administration on the organic content of silkworm, Bombyx mori. Indian Journal of Comparative Animal Physiology 4: 9-12.

Bharathi, D and Govindappa, S. (1987). Effect of prostaglandin F2 on the growth pattern of the silk worm larvae of Bombyx mori. XV International Sericultural Congress, Sericologia 27: 350-358.

Bharathi, D and Miao Yungen (2003). Changes in the protein and lipid profiles of silkworm, Bombyx mori L. infected with NPV. Bulletin of Indian Academy of Sericulture 7: 76-80.

Bhaskar, M. Bharathi, D. Redanna, P and Govindappa, S. (1983). Growth and biochemical composition of silk gland of Bombyx mori $\mathrm{L}$. on exposure to pituitary extract. National Seminar on Silk Research and Development. pp. 28-32.

Bose, P.C. Majumder, S.K and Sengupta, K. (1989). Role of amino acids in silkworm, Bombyx mori (L). Nutrition and their occurrence in haemolymph, silkgland and silk cocoon. Indian Journal of Sericulture 28: 17-31.

Chaudhuri, A and Medda, A.K. (1992). Thyroxine-induced alterations in glycogen content of fat body of female silkworm Bombyx mori (race Nistari) during larval, pupal and adult stages of development. Annals of Entomology
10: $17-21$.

Chen, P.S. (1971). Biochemical aspects of insect development. In: Monograph in developmental biology. (Wolsky, A. and Tarrytown, N.Y., eds.) Karger, Basel, 3: 230.

Child, S.Z., Carstensen, E.L and Law, W.K. (1981). Effects of ultrasound on Drosophila: III. Exposure of larvae to low temporal-average-intensity pulsed irradiation. Ultrasound in Medicine and Biology 7: 167.

Colowick, S.P and Kaplan, N.O. (1957). Methods in Enzymology. Academic Press, New York, 63: 28 .

Davis, N.C and Smith, E.L. (1955). Assay of proteolytic enzymes. Methods of Biochemical Analysis 2: 215-257.

Eguchi, $\mathrm{M}$ and Ivamoto, A. (1975). Changes in protease, esterase and phosphatase in the alimentary canal of the silkworm during metamorphosis. Insect Biochemistry 5: 495-507.

Fukuda, T. (1960). Biochemical studies on the formation of silk protein, XII. The functional localization of the silk gland on the amino acid absorption. Journal of Sericulture Science of Japan 29: 415.

Gakhar, S.K and Maleyvar, R.P. (1985). Ontogenic variations in carbohydrate, lipid and protein contents in Tabala vishnou (Lepidoptera - Insecta). The Proceedings of the National Academy of Sciences, India. 51B: 461-467.

Horie, Y and Watanabe, K. (1983). Effect of various kinds of dietary protein and supplementation with limiting amino acids on growth, haemolymph components and uric acid excretion in the silkworm, Bombyx mori. Journal of Insect Physiology 29: 187-199.

Horie, Y., Watanabe, K and Shirohara, E. (1971). Effect of dietary composition on growth, silkglands and components in haemolymph of the silkworm. Acta Sericulture Japan 78: 44-50.

Koehler, P.G.; Patterson, R.S and Webb, J.C. (1986). Efficacy of ultrasound for German 
cockroach (Orthoptera: Blattellidae) and oriental rat flea (Siphonaphera: Pulicidae) control. Journal of Economic Entomology 79: 10271031.

Krishna Murthy, C.V. Hurkadli, H.K and Thyagaraja, B.S. (1987). Effect of thyroxine on the growth and development of the silkworm, Bombyx mori. Journal of Sericulture of Japan 56: 351-352.

Lehninger, A.L. (1993). Biochemistry, $2^{\text {nd }}$ ed. Kalyani Publishers, Ludhiana, New Delhi.

Lee, Y.L and Lardy, H.A. (1965). Influence of thyroid hormones on phosphate dehydrogenase and other dehydrogenases in various organs of the rat. Journal of Biological Chemistry 240: 1427-1432.

Lele, P.P. (1973). Mechanisms of tissue-ultrasound interaction. Ultrasonics in Medicine, Proc. $2^{\text {nd }}$ World Congress (M. Delieger, D.N. White and V.R. McCready, eds.), Excerpta Medica, Amsterdam.

Lowry, O.H. Rosenbrough, N.J. Farr, L and Randall, R.J. (1951) Protein measurement with Folin phenol reagent. Journal of Biological Chemistry 193: 265-275.

Martin, M.D. Kinner, J.F and Thomas, J.A. (1971). Developmental changes in the late larvae of Calliphora stygia. IV. Uptake of plasma protein by the fat body. Australian Journal of Biological Science 24: 291-299.

Mathavan, S. Baskran, K. Sironmani, A and Pandian, T.J. (1984). Studies on the utilization of single cell protein by the silkworm, Bombyx mori. Entomology Experiments and Application 36: 61-68.

Moore, S and Stein, W.A. (1954). A modified ninhydrin reagent for the photometric determination of amino acids and related compounds. Journal of Biological Chemistry 211: 907-913.

Murali Mohan, P and Siva Prasad, S. (2013). Improvement in economic traits of the silkworm Bombyx mori L. by exposure to ultrasound. In- ternational Journal of Biotechnology Research 1: 103-110.

Nagata, M and Kobayashi, M. (1990). Quantitative changes in storage proteins during larval development of silkworm, Bombyx mori. Journal of Sericulture Science of Japan 59: 461-468.

Noguchi, A. Takeshita, $\mathrm{H}$ and Shigematsu, H. (1974). Interrelationships between the silkgland and other tissues in protein metabolism in the latest larval stage of the silkworm, Bombyx mori. Journal of Insect Physiology 20: 783794.

Ogawa, K and Tojo, S. (1981). Qualitative changes of storage proteins and vitellogenin during the pupal and adult development in the silkworm, Bombyx mori (Lepidoptera: Bombycidae). Applied Entomology and Zoology 16: 288-296.

Osanai, M. Aigaki, T and Kosuga, H. (1987). Arginine degradation cascade as an energy yielding system for sperm maturation in the spermatophore of silkworm Bombyx mori. In: New Horizons in Sperm Cell Research (P.P. Mohr, Ed.), pp. 185-195.

Pant, R and Jaiswal, G. (1981). Photoperiodic effect on transaminase activity, protein and total free amino acid content in the fat body of diapausing pupae of the tasar silkworm Antheraea mylitta. Indian Journal of Experimental Biology 19: 998-1000.

Price, G.M. (1973). Protein and nucleic acid metabolism in insect fat body. Biological Reviews 4B: 333-375.

Ravikumar, H, N and Sarangi, S.K. (2004). Changes in protein and total sugar content in eri silkworm, Philosamia ricini during fifth instar development. Bulletin of Indian Academy of Sericulture 8: 17-22.

Reitman, S and Frankel, S. (1957). A colorimetric method for the determination of serum glutamic-oxaloacetic and glutamic-pyruvic transaminases. American Journal of Clinical Pathology 28: 56 . 
Robert, B.G and Rutt, M.F. (1982). Protein synthesis during early, adult and $2^{\text {nd }}$ pupal development in silk moth A. polyphemus. Insect Biochemistry 12: 687-698.

Saha, B.N and Khan, A.R. (1977). Effect of vertebrate sex hormones on Bombyx mori L. Sericologia 37: 19-25.

Samal, S.K., Kaplan, D.L and Chiellini, E. (2013). Ultrasound sonication effects on silk fibroin protein. Macromolecular Materials and Engineering 298: 1201-1208.

Sarangi, S.K. (1985) Studies on the silkgland of Bombyx mori: A comparative analysis during fifth instar development. Proceedings of Indian Academy of Sciences (Animal Science) 94: 413-419.

Sasaki, S., Nakagima, E., Yoshiaki Fu-Jii-Kuriyama and Tashiro, Y. (1981). Intracellular transport and secretion of fibroin in the posterior silk gland of the silkworm. Journal of Cell Science 50: 19-44.

Singh, B.Dand Datta, S. (1980). Effect of cyclic AMP and prostaglandin E on post-embryonic development of silkworm, Bombyx mori L. Indian Journal of Entomology 42: 197-201.

Sinha, A.K. Sinha, U.S.P. Sinha, S.S and Sengupta, K. (1991). Studies on free amino acids, proteins, carbohydrates and phosphorous compounds in the tissue extracts of healthy and pebrine infected moths of Tasar silkworm, $A n$ theraea mylitta D. Indian Journal of Sericulture 30: 103-106.

Siva Prasad, S and Murali Mohan, P. (1990). Amino acids, aminotransferases and proteins in the metamorphosing silkworm, Bombyx mori L. Proceedings of Indian Academy of Sciences (Animal Science) 99: 369-375.
Thyagaraja, B.S. Master, E.P. Kelly, T.J and Borkovec, A.B. (1991). Thyroxine induced haemolymph protein and ecdysteroid increases in the silk worm, Bombyx mori L. Effect on larval growth and silk production. Journal of Insect Physiology 37: 153-160.

Tojo, S. Agata, M and Kobayashi, M. (1980). Storage proteins in the silkworm Bombyx mori. Insect Biochemistry 10: 289-303.

Urbesek F. (1989) Variations of aminotransferase activity in the gut of Bombyx mori during metamorphosis. Acta Entomogica Bohemostov 86: $336-341$.

Venkata Rami Reddy, K. Ramadevi, O.K. Magadum, S.B. Benchamin, K.V. and Datta, R.K. (1992) Uzi parasitisation and gluconeogenic precursor levels and related enzyme activity proteins in silkworm, Bombyx mori L. Indian Journal of Sericulture 31: 123-129.

Wanger Li and Yu Ting Sen (1982) Studies on the metabolism of amino acids in the silkworms. Formation of carbon skeleton of alanine from malic acid in Bombyx mori and Philosamia cynthia ricini. Acta Entomologica 25: 11-18.

Woeber, K. (1965) The effect of ultrasound in the treatment of cancer. In: Ultrasonic energy (E. Kelly, Ed.), University of Illinois Press, Urbana, USA.

Yamaoka, K. Hoshino, M. and Hirai, T. (1971) Role of sensory hairs on the anal papillae in oviposition behaviours of Bombyx mori. Journal of Insect Physiology 47: 2327-2336.

Zaidi, Z.S. and Khan, M.A. (1979) Changes in the total protein level of the haemolymph of Pysdercus cingulatus Fabr. (Hemiptera: Pyrrhocoridae) as related to metamorphosis and age. Journal of Animal Morphology and Physiology 26: 182-187. 